\title{
DESAIN MEDIA PROMOSI DAN KOMUNIKASI VISUAL PADA YAYASAN SMK ISLAM BAIDHAUL AHKAM KOTA TANGERANG
}

\author{
Andriyanto ${ }^{1}$, Dianarti Muhyani*2 \\ ${ }^{1,2}$ Program Studi Teknik Informatika Universitas Raharja \\ e-mail : ${ }^{1}$ andri.yanto@raharja.info, ${ }^{2 *}$ dianarti@raharja.info
}

\begin{abstract}
ABSTRAK
Melalui media gambar, warna, dan teks informasi menjadi lebih jelas dan menarik. Khususnya dalam bidang publikasi, multimedia menjadi salah satu media pendukung dalam penyampaian informasi yang efektif, serta lebih menarik dalam penyajiannya. Dari waktu ke waktu, kebutuhan masyarakat terhadap desain yang kreatif, efisien, dan efektif semakin bertambah.Perkembangan dunia pendidikan yang semakin pesat, menyebabkan semakin banyaknya fasilitas dan keunggulan yang harus dipromosikan untuk bersaing dengan sekolah lain khususnya pada yayasanSMK Islam Baidhaul Ahkam. Permasalahan yang terdapat pada SMK Islam Baidhaul Ahkam saat ini, dalam strategi promosinya masih menggunakan desain yang kurang informatif untuk calon siswa/i baru sehingga membuat minat mereka kurang untuk melihat SMK Islam Baidhaul Ahkam. Metode penelitian yang digunakan adalah observasi, wawancara dan studi pustaka. Melalui perancangan desain yang lebih menarik dan up to date diharapkan calon siswa/i baru dapat mengetahui informasi yang update dan tertarik untuk bersekolah SMK Islam Baidhaul Ahkam serta semakin dikenal khalayak luas.
\end{abstract}

Kata Kunci : Pendidikan, Publikasi, SMK Islam Baidhaul Ahkam.

\begin{abstract}
Through media images, colors, and information texts become more clear and interesting. Especially in the field of publications, multimedia has become one of the supporting media in the delivery of effective, and more interesting information in its presentation. From time to time, people's needs for creative, efficient and effective designs are increasing. The development of the world of education is increasingly rapid, leading to the increasing number of facilities and advantages that must be promoted to compete with other schools, especially at the Baidhaul Ahkam Islamic Vocational School foundation. Current problems in the Baidhaul Ahkam Islamic Vocational School, in its promotional strategy, still use less informative designs for new prospective students, making them less interested in seeing Baidhaul Ahkam Islamic Vocational Schools. The research method used is observation, interview and literature study. Through a more attractive and up-to-date design design, it is expected that new students can find out updated information and are interested in attending Baidhaul Ahkam Islamic Vocational School and becoming more widely known to the wider audience.
\end{abstract}

Keywords: Education, Publication, Baidhaul Ahkam Islamic Vocational School. 


\section{PENDAHULUAN}

Desaingrafis adalah suatu bentuk komunikasi visual yang menggunakan gambar untuk menyampaikan informasi atau pesan seefektif mungkin. Dalam desain grafis, teks juga dianggap gambar karena merupakan hasil abstraksi simbol-simbol yang bisa dibunyikan. Desain grafis diterapkan dalam desain komunikasi dan "fine art". Seperti jenis desain lainnya, desain grafis dapat merujuk kepada proses pembuatan, metoda merancang, produk yang dihasilkan rancangan, atau pun disiplin ilmu yang digunakan desain.

Promosi merupakan komunikasi antara perusahaan dan konsumen secara implisit berlangsung pada setiap unsur atau bagian dari marketing mix, namun sebagian besar komunikasi perusahaan berlangsung sebagai bagian dari suatu program promosi yang diawasi dan direncanakan dengan hatihati.

Media merupakan target konsumen yang paling mudah dijangkau sedangkan audiensi yang jarang menggunakan media adalah kelompok target konsumen yang paling sulit dijangkau. Dengan kata lain, kita tidak perlu membuang waktu dan tenaga untuk memanjat hingga ke puncak pohon guna mendapatkan buah diujung dahan (untuk menjangkau target konsumen yang memang sulit di jangkau) hingga seluruh buah yang mudah dijangkau bisa kita petik.

Desain grafis digunakan sebagai alat komunikasi seperti diterapkan untuk media-media statis, seperti buku, majalah, dan brosur, catalog flyer, pamphlet Koran, dll. Sebagai tambahan, sejalan dengan perkembangan zaman, desain grafis juga diterapkan dalam media elektronik, yang sering kali disebut sebagai desain interaktif atau desain multimedia.

Pada dasarnya media komunikasi visual berupa desain promosi sangat membantu bagi para siswa/i yang ingin mengetahui informasi agar lebih efektif dan informatif dalam penyebaran promosi,sehingga banyak calon siswa/i yang tertarik untuk bersekolah di SMK Islam Baidhaul Ahkam.

\section{METODE PENELITIAN}

Untuk memperoleh data yang diperlukan dalampenelitian ada beberapa metode antara lain, Observasi adalah pengambilan data yang diperlukan untuk penyusunan laporan melalui pengamatan dan membuat pencatatan secara sistematik terhadap unsur - unsur yang telah diteliti, selanjutnya wawancara ( Interview)adalah pengumpulan data dengan cara bertatap muka langsung dengan orang yang akan diwawancarai, untuk memperoleh informasi langsung kepada pihak - pihak yang terkait di SMK Islam Baidhaul Ahkam. Wawancara dilakukan dengan Bapak Agus Salim pada tanggal 15 Oktober 2018 sebagai wakil kepala sekolah dan yang terakhir study Pustaka, Selain melakukan observasi dan wawancara, study pustaka adalah pengumpulan data berupa teori, mempelajari dan memahami buku - buku, jurnal dan proceeddings yang berkaitan dengan penulisan.

Setelah melakukan beberapa studypustaka, berikut adalah beberapa penelitian yang digunakan sebagai acuan dalam penelitian ini:

1. Penelitian yang dilakukan oleh Maylan (2014) STMIK Raharja yang berjudul "Perancangan Media Company Profile Sebagai Penunjang Informasi Dan Promosi Pada Smk Primawisata" penelitian ini menjelaskan tentang pembuatan media promosi sebagaisarana promosi pada Smk Primawisata. Media promosi ini yang akan digunakan untuk meningkatkan citra atau image sekolah dan meningkatkan kuantitas jumlah calon siswa yang mendaftar setiap tahunnya, Selain itu dapat mempermudah petugas penerimaan siswa baru dalam menjelaskan ruang lingkup kepada orang tua atau calon siswa baru.

2. Penelitian yang dilakukan oleh Hadinata (2016) Universitas Kristen Petra yang berjudul "Perancangan Identitas Visual Dan Promosi Ayam Goreng "Queen Wings" Di Kota 
Surabaya" penelitian ini menjelaskan tentang perancangan identitas visual dan promosi Ayam Goreng Queen Wings. Awalnya Queen Wings sendiri diperkenalkan oleh Ibu Liana hanya sebatas teman reuni dan dari mulut ke mulut saja, serta tidak ada brosur dan logosebagai sebagai media pendukung promosi, oleh karena itu melalui perancangan ini diharapkan Queen Wings dapat mengenalkan mereknya sekaligus spesifikasi produk yang ditawarkan kepada masyarakat Surabaya. Selain itu diharapkan pula dapat menarik minat calon konsumen akan produk yang dijual Queen Wings melalui kelebihan dan keunikannya sehingga dapat menciptakan brand experiencebagi konsumen.

2. Penelitian yang dilakukan oleh Tobiasson (2015) yang berjudul "Designing for Active Life: Moving and Being Moved Together with Dementia Patients"

Life for older people with dementia tends to be inactive. This paper reports on two case studies in which exercise games (exergames) were introduced in dementia special care units with a focus on patients' well-being. The first case used a participatory design (PD) approach to engage the patients as users in the process. The results highlight the patients' enjoyment in playing these games in a socially encouraging environment. We have found that exergames in dementia care provide patients with the well-documented health benefits of physical activity and also result in social and cognitive benefits. The results indicate that the notions of games/competition, social interaction, physical activity and challenges are valuable ingredients when designing for the well-being of older people who suffer from moderate to severe dementia.

3. Penelitian yang dilakukan oleh Putri (2014)STMIK Raharja yang berjudul "Perancangan Media Desain Komunikasi Visual Sebagai sarana Penunjang Promosi Pada Cv. Kurnia Vision Tangerang" penelitian ini menjelaskan Perancangan media penunjang promosi untuk penunjang penyampaian informasi perusahaan CV. Kurnia Vision direncanakan berupa: Media yang digunakan sebagai (souvenir) kenang-kenangan sekaligus sebagai pencitraan dari perusahaan $\mathrm{CV}$.

4. Penelitian yang dilakukan oleh Maria (2017) Universitas STMIK raharja yang berjudul "PENGEMBANGAN MEDIA INFORMASI PADA RUMAH SAKIT KUSTA Dr. SITANALA TANGERANG" penelitian ini menjelskan perancangan komunikasi visual sebagai media menyampaikan informasi kepada masyarakat. Baik informasi tentang kesehatan maupun pelayanan pada Rumah Sakit Kusta Dr. Sitanal. Belum maksimal karna desain yang kurang menarik dalam menyampaikan informasi, sehingga mendapatkan respon yang tidak begitu baik dari pasien dan pengunjung Rumah Sakit Kusta Dr. Sitanala.

\section{HASIL DAN PEMBAHASAN}

\section{Perencanan Media (Konsep Media)}

Dalam hal ini, konsep media yang diajukan adalah perancangan Desain Promosi. Desain Promosi ini berisi tentang info yang berkaitan dengan sekolah serta kegitan siswa/i SMK Islam Baidhaul Ahkam, Sejarah, visi, dan misi, tujuan dsb. Semua isi yang terkait dalam pembuatan merchandise tersebut dikemas dengan menggunakan pengembangan kreatif desain grafis.

\section{Perencanaan Pesan (Konsep Kreatif)}

Konsep kreatif pada media Desain Promosi ini, penulis mencoba menuangkan ide ide kreatif berdasarkan data data objek yang diperoleh dari SMK Islam Baidhaul Ahkam yang kemungkinan diolah dalam sebuah desain sesuai dengan alur proses kreatif dan disesuaikan dengan kebutuhan SMK Islam Baidhaul Ahkam. 


\title{
Konsep Desain
}

1. Spanduk Ucapan Selamat datang SMK Islam Baidhaul Ahkam (Sudah diterima bagian pemasaran)

\section{a. Latar Belakang}

Media Spanduk Ucapan Selamat datang dibuat dalam rangka penunjang daya tarik masyarakat, untuk mengucapkan selamat datang kepada masyarakat dalam rangka penerimaan calon siswa/i baru.

Karakteristik Sasaran Demografi :

1. Jenis Kelamin : Pria dan Wanita

2. Kelas Ekonomi : Semua Jenis Kalangan

3. Sasaran : Untuk Siswa/i dan Guru SMK Islam Baidhaul Ahkam

4. Karakteristik Sasaran Geografi: Peserta didik baru

b. Konsep Desain

- Image :

Desain Spanduk ini dibuat dengan ukuran $(200 \mathrm{~cm}$ x $90 \mathrm{~m})$ dengan menggunakan gambar logo sekolah, dan logo SMK Bisa

- Warna :

Pada desain spanduk menggunakan latar belakang warna hijau gradasi kuning, dan warna merah pada tulisan

- Font :

Roboto dan Vijaya.

c. Rancangan Visual

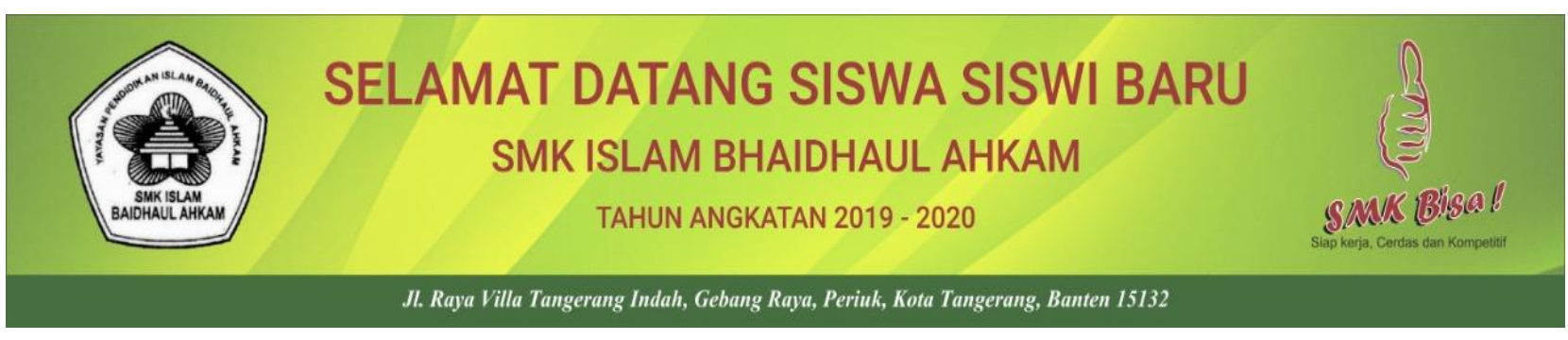

Gambar 2. Spanduk Ucapan Selamat Datang

2. Spanduk Penerimaan Siswa/i Baru SMK Islam Baidhaul Ahkam (Sudah diterima bagian pemasaran)

\author{
a. Latar Belakang \\ Media Spanduk Penerimaan Siswa/i baru dibuat dalam rangka penunjang daya \\ tarik masyarakat, dalam rangka penerimaan calon siswa atau siswi baru. \\ Karakteristik Sasaran Demografi : \\ 1. Jenis Kelamin : Pria dan Wanita \\ 2. Kelas Ekonomi $\quad$ : Semua Jenis Kalangan \\ 3. Sasaran : Untuk Siswa/i dan Guru SMK Islam Baidhaul Ahkam \\ 4. Karakteristik Sasaran Geografi : Peserta Didik Baru \\ b. Konsep Desain \\ - Image :
}


Desain Sepanduk ini dibuat dengan ukuran $(200 \mathrm{~cm}$ x 90m) dengan menggunakan gambar logo sekolah, dan di beri beberapa gambar kegiatan ekstrakulikuler.

- Warna : pada desain spanduk menggunakan latar belakang warna hijau gradasi kuning.

- Font :

Roboto dan Vijaya

c. Rancangan Visual

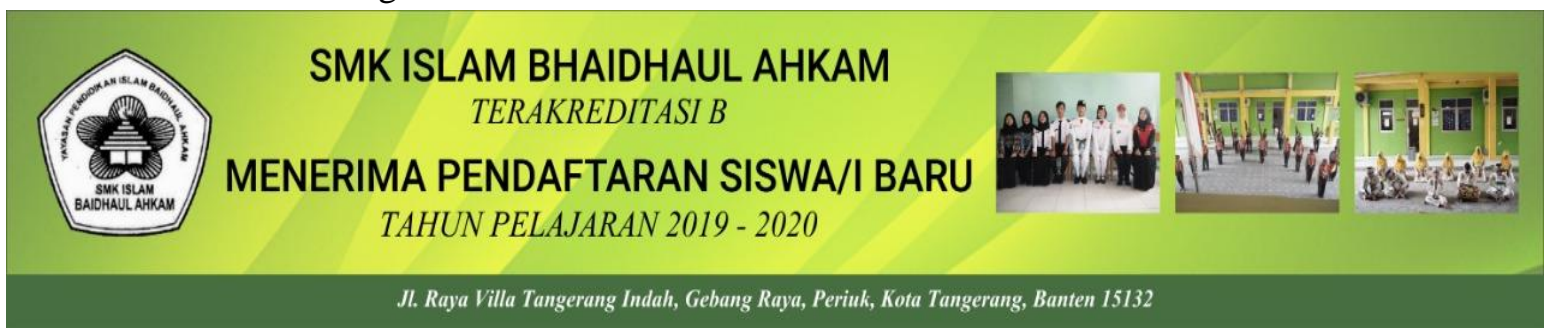

Gambar 3.

Desain Spanduk Penerimaan Peserta Didik Baru SMK Islam Baidhaul Ahkam

3. Desain Flayer SMK Islam Baihaul Ahkam (Sudah diterima bagian pemasaran)

a. Latar Belakang

Media Desain Flayer dibuat dalam rangka penunjang daya tarik masyarakat, dalam rangka penerimaan calon siswa atau siswi baru.

Karakteristik Sasaran Demografi :

1. Jenis Kelamin : Pria dan Wanita

2. Kelas Ekonomi $\quad$ :Semua Jenis Kalangan

3. Sasaran : Untuk calon Siswa/i SMK Islam Baidhaul Ahkam

4. Karakteristik Sasaran Geografi : Peserta Didik Baru

b. Konsep Desain

- Image :

Desain Flayer ini dibuat dengan ukuran $(14.8 \mathrm{~cm}$ x $21 \mathrm{~cm})$ dengan menggunakan gambar logo sekolah, dan di beri beberapa gambar kegiatan ekstrakulikuler.

- Warna :

pada desain flayer menggunakan latar belakang warna putih dan hijau

- Font :

Roboto dan Vijaya

c. Rancangan Visual 


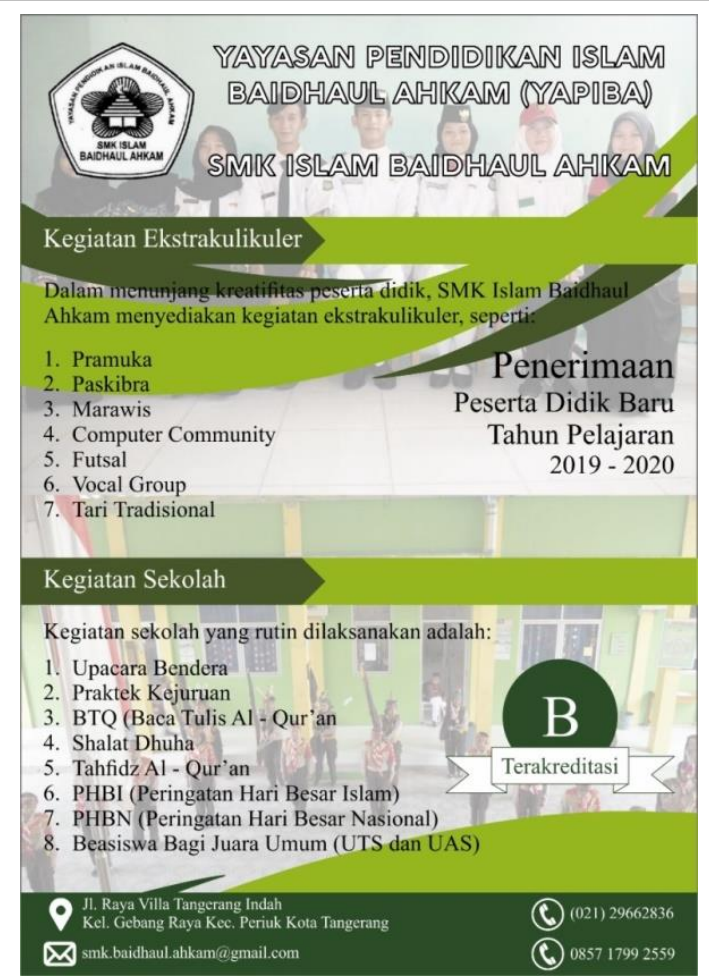

Gambar 4.

Desain Flyer SMK Islam Baidhaul Ahkam

4. Desain Kalender SMK Islam Baidhaul Ahkam (Sudah diterima bagian pemasaran)

a. Latar Belakang

Desain Kalender merupakan media yang diletakkan dikantor Sekolah maupun di kelas-kelas yang ada di Sekolah SMK Islam Baidhaul Ahkam.

Karakteristik Sasaran Demografi :

1. Jenis Kelamin : Pria dan Wanita

2. Kelas Ekonomi : Semua Jenis Kalangan

3. Sasaran : Untuk Siswa/i SMK Islam Baidhaul Ahkam

4. Karakteristik Sasaran Geografi : Untuk Siswa/i SMK Islam Baidhaul Ahkam

b. Konsep Desain

- Image :

Desain Kalender ini dibuat dengan ukuran $(55 \mathrm{~cm}$ x $38 \mathrm{~cm})$ dengan menggunakan gambar kegiatan sekolah.

- Warna:

Pada desain kalender ini menggunakan warna hijau dan putih

- Font :

Riffic Free Medium

c. Rancangan Visual 


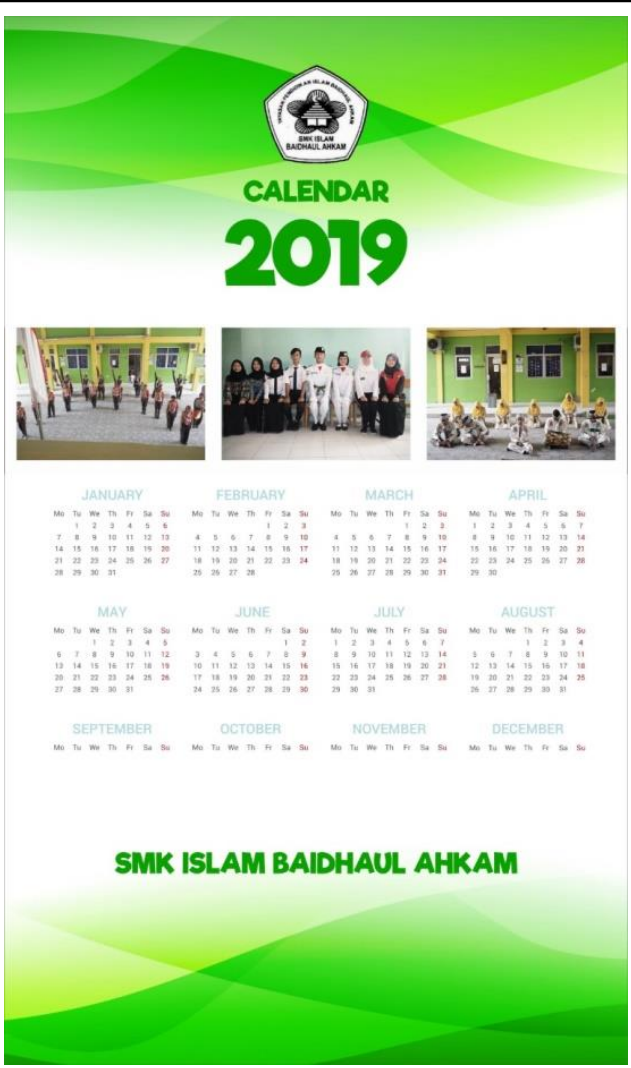

Gambar 5. Kalender 2019 SMK Islam Baidhaul Ahkam

5. Desain Jam Dinding SMK Islam Baidhaul Ahkam (Sudah diterima bagian pemasaran)

a. Latar Belakang

Desain jam dinding merupakan media yang diletakkan dikantor Sekolah maupun di kelas-kelas yang ada di Sekolah SMK Islam Baidhaul Ahkam. Ukuran diameter jam ini adalah $28 \mathrm{~cm}$

Karakteristik Sasaran Demografi :

1. Jenis Kelamin : Pria dan Wanita

2. Kelas Ekonomi : Semua Jenis Kalangan

3. Sasaran : Untuk Siswa/i SMK Islam Baidhaul Ahkam

4. Karakteristik Sasaran Geografi : Untuk Siswa/i SMK Islam Baidhaul Ahkam

b. Konsep Desain

- Image :

Desain jam dinding ini dibuat dengan ukuran 500 pixel x 500 pixel dengan menggunakan gambar logo sekolah.

- Warna :

pada desain jam dinding ini menggunakan warna hijau

- Font :

Roboto dan Vijaya

c. Rancangan Visual 


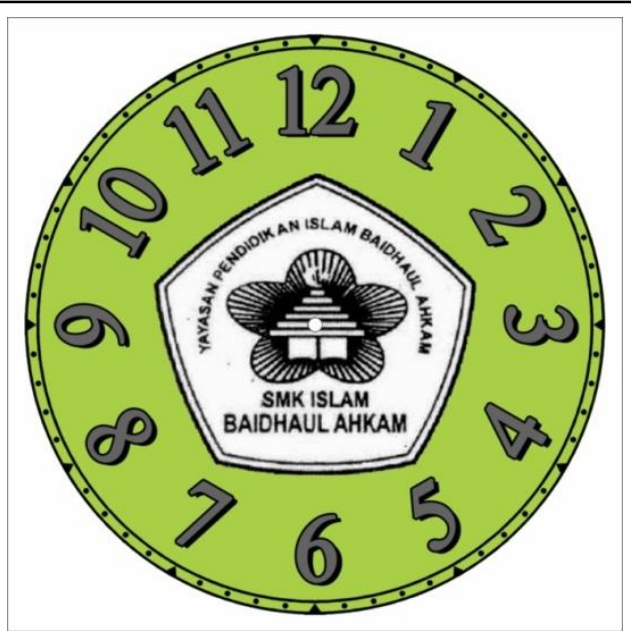

Gambar 6. Jam dinding Smk Islam Baidhaul Ahkam

6. Desain Sampul Buku SMK Islam Baidhaul Ahkam (Sudah diterima bagian pemasaran)

a. Latar Belakang

Media Desain sampul buku ini dibuat untuk para siswa-siswi SMK Islam Baidhaul Ahkam agar terlihat rapih.

Karakteristik Sasaran Demografi :

1. Jenis Kelamin : Pria dan Wanita

2. Kelas Ekonomi : Semua Jenis Kalangan

3. Sasaran : Untuk Siswa/i SMK Islam Baidhaul Ahkam

4. Karakteristik Sasaran Geografi: Untuk Siswa/i SMK Islam Baidhaul Ahkam

b. Konsep Desain

- Image :

Desain Sampul buku ini dibuat dengan ukuran $(29.6 \mathrm{~cm} \times 21 \mathrm{~cm})$ dengan menggunakan gambar logo sekolah, dan beberapa gambar ekstrakulikuler

- Warna:

Pada desain buku sampul ini menggunakan latar belakang warna hijau dan warna putih yang telah di Transparency

- Font :

Aquawax, Times New Roman, dan Vijaya

c. Rancangan Visual 


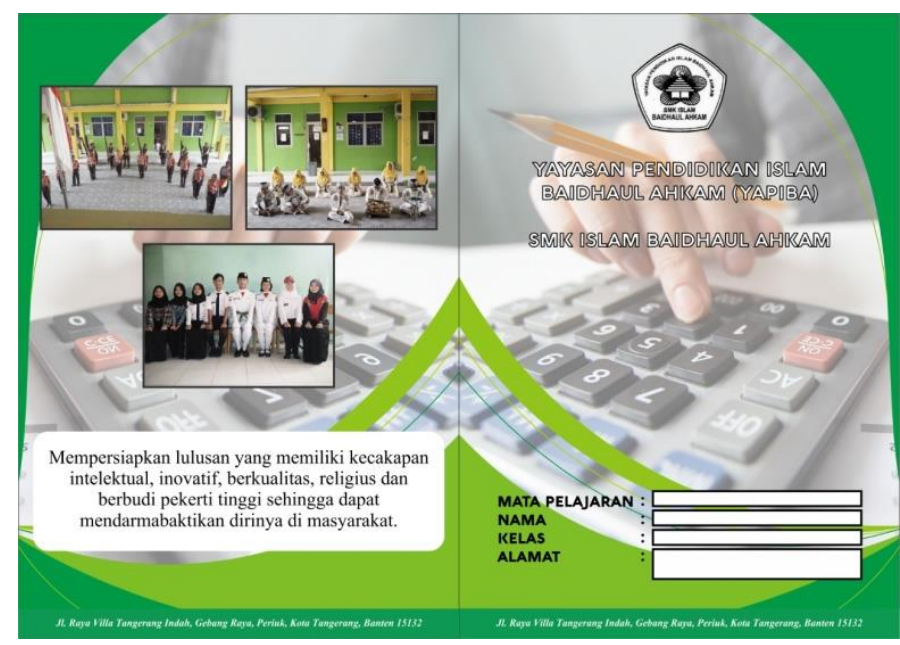

Gambar 7. Desain Buku Sampul

\section{KESIMPULAN}

Dengan adanya penelitian ini kita bisa lebih memahami lebih rinci tentang Desain grafis terutama untuk media promosi pada sekolah. karena itulah dapat ditarik kesimpulan bahwa masalah yang dihadapi yaitu desain media cetak sebelumnya belum mampu menarik calon siswa/siswi SMK Islam Baidhaul Ahkam dan masih membutuhkan pembaruan (update) desain yang lebih menarik serta fresh yang mampu menarik masyarakat. Maka dari itu dibuat penambahan media promosi desain seperti flayer, brosur, spanduk dan kalender agar calon siswa/siswi baru bisa mengetahui informasi serta keunggulan yang ada di sekolah SMK Islam Baidhaul Ahkam. Mengetahui seperti apa seluk beluk dunia kerja dan pengalaman kerja yang sebenarnya,bisa memperluas ilmu pengetahuan ilmiah khususnya pada bidang Desain Grafis, serta paham berbagai macam aplikasi yang digunakan seorang desainer grafis dalam dunia kerja. Selain itu media desain promosi yang lebih menarik juga dapat membantu calon siswa/siswi untuk mengetahui informasi yang ada pada sekolah dan bisa tahu lebih jelas tentang kegiatan yang ada di sekolah (ekstrakulikuler).

\section{DAFTAR PUSTAKA}

[1] Asmarani, Maylan (2014). Perancangan Media Company Profile Sebagai Penunjang Informasi Dan Promosi Pada SMK Primawisata. Tangerang : STMIK RAHARJA

[2] Hadinata, Alfyn, Ahmad Adib, Anang Tri Wahyudi. 2016. Perancangan Identitas Visual Dan Promosi Ayam Goreng "Queen Wings" Di Kota Surabaya. Jurnal DKV Adiwarna. Surabaya : Universitas Kristen Petra. Vol. 1, No 8. Diambil dari :https://goo.gl/aYaiA6. (31 November 2017

[3] Morissan. 2014. Teori Komunikasi Individu Hingga Massa. Jakarta: Kencana Prenadamedia Group.

[4] Novena, Maria Dingi. 2017. PENGEMBANGAN MEDIA INFORMASI PADki9A RUMAH SAKIT KUSTA Dr. SITANALA TANGERANG. Tangerang : STMIK raharja.

[5] Putri, Novianti Dwi. 2014. Perancangan Media Desain Komunikasi Visual Sebagaisarana Penunjang Promosi Pada Cv. Kurnia VisionTangerang. Tangerang : STMIK Raharja. 
[6] Rosalina, Vidila. Ahmad Kausar. Dan Yusuf Fazri Sutiawan. 2015.Perancangan Video Company Profile Kota Serang Dengan Teknik Editing Menggunakan Adobe Premiere Pro CS 5. Serang :Universitas Serang Raya. Jurnal PROSISKO. ISSN(o): 2249-7382. Vol.2, No.1:2.

[7] Tobiasson, Helena, Yngve Sundblad, Åke Walldius, and Anders Hedman. 2015. Designing for Active Life: Moving and Being Moved Together with Dementia Patients. International Journal Of Design. Stockholm: Kungliga Tekniska högskolan (KTH) (engelska: KTH Royal Institute of Technology). Vol. 9 No. 3. Diambil dari : https://goo.gl/oXLKfL. (06 November 2017) 